\title{
Metabolic Syndrome-Role of Dietary Fat Type and Quantity
}

\section{Peter Clifton}

School of Pharmacy and Medical Sciences, University of South Australia, Adelaide SA 5000, Australia; peter.clifton@unisa.edu.au

Received: 27 May 2019; Accepted: 24 June 2019; Published: 26 June 2019

\begin{abstract}
Background: Metabolic syndrome increases the risk of cardiovascular disease (CVD) over and above that related to type 2 diabetes. The optimal diet for the treatment of metabolic syndrome is not clear. Materials and Methods: A review of dietary interventions in volunteers with metabolic syndrome as well as studies examining the impact of dietary fat on the separate components of metabolic syndrome was undertaken using only recent meta-analyses, if available. Results: Most of the data suggest that replacing carbohydrates with any fat, but particularly polyunsaturated fat, will lower triglyceride(TG), increase high density lipoprotein (HDL) cholesterol, and lower blood pressure, but have no effects on fasting glucose in normal volunteers or insulin sensitivity, as assessed by euglycemic hyperinsulinemic clamps. Fasting insulin may be lowered by fat. Monounsaturated fat (MUFA) is preferable to polyunsaturated fat (PUFA) for fasting insulin and glucose lowering. The addition of 3-4 g of N3 fats will lower TG and blood pressure (BP) and reduce the proportion of subjects with metabolic syndrome. Dairy fat ( $50 \%$ saturated fat) is also related to a lower incidence of metabolic syndrome in cohort studies.
\end{abstract}

Keywords: carbohydrate; polyunsaturated fat; monounsaturated fat; saturated fat; fish oil; meta-analyses; lipids; glucose; blood pressure; insulin resistance

\section{Introduction}

The metabolic syndrome is associated with an increased risk of cardiovascular disease and type 2 diabetes and enhances the risk of CVD in people with diabetes [1]. There are currently four definitions of metabolic syndrome, three of which require insulin resistance, as evidenced by central obesity, or fasting hyperinsulinemia or a disturbance in glucose homeostasis, plus two other abnormalities [2]. The National Cholesterol Education Program Adult Treatment Panel (NCEP ATP-III (revision 2005) guidelines does not require this, but demands 3 of 5 possible abnormalities-central obesity, impaired fasting glucose, hypertriglyceridemia, low HDL cholesterol, and blood pressure ( $>130$ systolic or $>85$ diastolic). The other criteria vary with different levels of blood pressure (140/90), with a combination of high TG and low HDL as one criterion, and varying levels of fasting TG—either 1.7 or $2 \mathrm{mmol} / \mathrm{L}$-and varying levels of HDL cholesterol. This review will focus on the components of the metabolic syndrome and where there are data on the presence or absence of metabolic syndrome, the criterion used will be mentioned. The aim of this review is to systematically examine meta-analyses that summarise the evidence from interventions on fat amount and type in metabolic syndrome or its separate components. Some evidence from individual trials that are illustrative will be included.

\section{Aim}

To systematically review meta-analyses of interventions that replace carbohydrates with fat in people with metabolic syndrome and interventions that examine these effects on the individual components of the syndrome. 


\section{Methods}

Pubmed was searched (all years available) with the terms "meta-analysis AND dietary fat AND carbohydrate AND intervention AND (TG, OR, HDL, OR blood pressure, OR glucose, OR weight)". We reviewed 102 titles.

\section{Results}

\subsection{Lipids}

A large amount of evidence has accumulated that replacing carbohydrates (usually quality unspecified) with fat of any sort will lower fasting triglyceride and increase HDL cholesterol. A meta-analysis by Mensink and Katan [3] found that a $1 \%$ increase in fat calories in place of carbohydrates led to a fall in TG of $0.026 \mathrm{mmol} / \mathrm{L}$ (95\% confidence intervals: $0.020-0.031)$ with polyunsaturated fat, 0.021 (0.015-0.027) with saturated fat, and 0.019 (0.014-0.024) with monounsaturated fat from 100 studies with 45 diets. For HDL cholesterol the same diets led to an increase in HDL cholesterol of $0.006(0.003-0.009) \mathrm{mmol} / \mathrm{L}, 0.010(0.007-0.013)$, and $0.008(0.005-0.011)$, respectively. Overall saturated fat is about $30 \%$ more effective than the other two fats in the combined lowering of TG and HDL cholesterol. However, differences in HDL cholesterol from genetic variance have not been associated with differences in coronary heart disease (CHD) risk [4], whereas TG lowering genetically has been associated with CVD reduction, with the same degree of benefit per $\mathrm{mg} / \mathrm{dL}$ apoB lowering as a reduction in LDL cholesterol [5]. Thus, PUFA is preferred to other fat types for carbohydrate replacement. In a small study of 39 men with metabolic syndrome, PUFA produced greater TG lowering than MUFA (both 5-30\% of energy). Overall, 25\% (4 of 16) assigned to PUFA and 13\% (3 of 23) to MUFA did not have metabolic syndrome after the intervention [6]. Metabolic syndrome in this study was based on NCEP-III (2001). A high total dairy intake (and, presumably, a lower carbohydrate diet) is associated with a $6 \%$ reduced risk of metabolic syndrome per additional serving of dairy [7]. Most studies in this meta-analysis of 16 case-control/cross-sectional studies used the NCEP-III criteria.

The relationship between carbohydrate intake and TG has been controversial for many years with arguments about the persistence of the TG elevation effect [8,9], with the moderating or even nullifying effect of fibre on TG elevation [10], the contrasting effects of higher versus lower sugar with sugars replacing starch [11,12], and the absence of TG elevation in Pima Indians with type 2 diabetes mellitus (DM) with increased carbohydrates [13]. Just when the landscape was reasonably predictable from interventions, the TOSCA.IT showed in 18,785 people with type $2 \mathrm{DM}$ that increasing fat intake from $<25 \%$ to $>35 \%$ increased TG, while increasing carbohydrate intake from $<45 \%$ to $>65 \%$ decreased TG [14]. TG was lower in the highest tertile of the relative Mediterranean diet score, which had lower added sugars, more fibre, but less fat and more carbohydrates. [15]. However, the TOSCA-IT is a large cohort study and its results may well be confounded as they do not match the results from dietary intervention studies in people with type $2 \mathrm{DM}$. The Qian meta-analysis [16] of 24 studies with 1460 participants showed that fasting TG was reduced by $0.31 \mathrm{mmol} / \mathrm{L}$ ( $95 \%$ confidence interval -0.44 , -0.18 ) with replacement of carbohydrates with MUFA. A high fibre intake is associated with a $30 \%$ lowering in the risk of metabolic syndrome [17].

In a meta-analysis of high-fat versus low-fat diets in people with obesity, but no overt metabolic disturbance, Lu et al. (2018) [18] found a significantly higher level of TG (WMD: $11.68 \mathrm{mg} / \mathrm{dL}$ (0.13 $\mathrm{mmol} / \mathrm{l}), 95 \% \mathrm{CI} 5.90,17.45 ; p<0.001$ ) and a lower level of HDL-cholesterol (WMD: $-2.57 \mathrm{mg} / \mathrm{dL}$ $(-0.07 \mathrm{mmol} / \mathrm{l}) ; 95 \% \mathrm{CI}-3.85,-1.28 ; p<0.001)$ after the low-fat diets, compared with high-fat diets in 20 studies with 2016 participants.

\subsection{Fish Oil Fatty Acids}

Guo et al. [19] performed a meta-analysis of seven case-control and 20 cross-sectional studies and found that a higher level of plasma/serum $n$-3 PUFAs was associated with a lower metabolic syndrome risk (pooled OR $=0.63,95 \%$ CI: $0.49,0.81$ ). The plasma/serum $n-3$ PUFAs in controls were significantly 
higher than in metabolic syndrome cases (WMD: 0.24; 95\% CI: 0.04, 0.43), especially docosapentaenoic acid and docosahexaenoic acid.

The addition of fish oil fatty acids of at least $1 \mathrm{~g} /$ day lowers fasting TG and a metanalysis performed by Eslick et al. [20] of 47 studies showed that taking fish oils (weighted average daily intake of $3.25 \mathrm{~g}$ of EPA and/or DHA) produced a clinically significant reduction of TG $(-0.34 \mathrm{mmol} / \mathrm{L}, 95 \% \mathrm{CI}:-0.41$ to $-0.27)$, with a very slight increase in HDL (0.01 mmol/L, 95\% CI: 0.00 to 0.02) and LDL cholesterol (0.06 $\mathrm{mmol} / \mathrm{L}, 95 \%$ CI: 0.03 to 0.09$)$. The reduction of TG correlated with EPA plus DHA intake and initial TG level.

\subsection{Glucose}

Fasting glucose lowering by reducing carbohydrate and replacing it with fat is far more controversial. A recent meta-analysis by Wanders et al. [21] showed no effect in normal subjects of replacing carbohydrate with polyunsaturated fat, even though fasting insulin was reduced. A $5 \%$ increase in energy from PUFA significantly reduced insulin by $5.8 \mathrm{pmol} / \mathrm{L}$ ( $95 \% \mathrm{CI}-10.2$ to -1.3 $\mathrm{pmol} / \mathrm{L}$ ), but not glucose (change $-0.07,95 \% \mathrm{CI}-0.17$ to $0.04 \mathrm{mmol} / \mathrm{L}$ ) and even in the group with the highest intake of PUFA, glucose was still not significant $(-0.09,95 \% \mathrm{CI}-0.18$ to $0.01 \mathrm{mmol} / \mathrm{L})$. Imamura et al. [22] found that replacing 5\% energy from carbohydrates with SFA had no significant effect on fasting glucose $(+0.02 \mathrm{mmol} / \mathrm{L}, 95 \% \mathrm{CI}=-0.01,+0.04 ; n$ trials $=99)$, but lowered fasting insulin $(-1.1$ $\mathrm{pmol} / \mathrm{L} ;-1.7,-0.5 ; n=90)$. Replacing saturated fat with PUFA lowered fasting glucose $(0.04 \mathrm{mmol} / \mathrm{L}$; $0.01,0.07)$. Thus, PUFA is clearly the better fat for replacing carbohydrates in normal people. In people with type 2 diabetes [16], high MUFA diets compared with high carbohydrate diets lowered fasting plasma glucose (WMD -0.57 mmol/L [95\% CI -0.76, -0.39]) in 24 studies containing 1460 participants. HDL cholesterol was increased by $0.06 \mathrm{mmol} / \mathrm{L}(0.02,0.10)$ [16]. Surprisingly, in this study, replacing PUFA with MUFA lowered fasting glucose by a large amount $(-0.87 \mathrm{mmol} / \mathrm{L}(-1.67,-0.07))$ but the data are much less reliable, taken from only four studies and 44 participants.

\subsection{Blood Pressure}

There are much less data on blood pressure and carbohydrate replacement with fat in non-diabetics and the effects are relatively small. A meta-analysis performed by Shah et al. [23] found that diets rich in carbohydrates resulted in significantly higher systolic blood pressure (difference: 2.6 (95\% CI: 0.4, 4.7) $\mathrm{mm} \mathrm{Hg} ; p=0.02)$ and diastolic blood pressure $(1.8(0.01,3.6) \mathrm{mm} \mathrm{Hg} ; p=0.05)$ than did diets rich in cis-monounsaturated fat. Huntress et al. [24] examined low carbohydrate diets in people with type 2 diabetes from data at one year. Eighteen trials were included in the meta-analysis, which found that the low carbohydrate diet lowered systolic blood pressure (estimated effect $=-2.74 \mathrm{mmHg}, 95 \% \mathrm{CI}$ -5.27 to -0.20$)$, but diastolic BP was not significant. In the meta-analysis from Qian et al. [16], MUFA lowered systolic blood pressure $(-2.31 \mathrm{mmHg}(-4.13,-0.49))$ when it replaced carbohydrates.

\subsection{Diet Composition During Weight Loss and Lipid Changes}

Mansoor et al. [25] performed a meta-analysis of 11 weight loss trials with 1369 participants with a low carbohydrate level being defined as $<20 \%$ carbohydrates. Compared with participants on low fat diets, participants on low carbohydrate diets experienced a greater reduction in body weight (weighted mean difference [WMD] -2.17 kg; 95\% CI -3.36, -0.99) and TG (WMD -0.26 mmol/L; 95\% CI -0.37, -0.15), but a greater increase in HDL-cholesterol (WMD 0.14 mmol/1; 95\% CI 0.09, 0.19) and LDL-cholesterol (WMD 0.16 mmol/L; 95\% CI 0.003, 0.33). Most of the low carbohydrate diets followed an Atkins style diet with an increase in saturated fat, which accounted for the rise in LDL cholesterol. If carbohydrates are replaced by unsaturated fat and not saturated fat, no rise in LDL cholesterol is seen in either six months [26], or one- [27] or two-year follow ups [28]. 


\subsection{Insulin Resistance}

Insulin resistance is a key and essential element of the metabolic syndrome (except the NCEP111 criteria), usually assumed on the basis of central adiposity. As noted by Wanders et al. [21], replacing carbohydrates with PUFA led to a lowering of fasting insulin, as did saturated fat, suggesting reduced insulin resistance, at least in the liver. There have been a small number of formal hyperinsulemic euglycemic clamp studies, but no meta-analysis. Tardy et al. [29] compared high dairy and industrial trans fatty acids with low trans fat diets in 63 healthy women with abdominal obesity. After four weeks of $60 \mathrm{~g}$ low-TFA lipids/day $(0.54 \mathrm{~g} /$ day; $n=21)$, ruminant TFA-rich lipids (4.86 g/day; $n=21)$, or industrial TFA-rich lipids (5.58 g/day; $n=21)$, no changes in peripheral insulin sensitivity were seen. Bendtsen et al. [30] found no effect either of $15 \mathrm{~g} /$ day of trans fat in partially hydrogenated soybean oil for 16 weeks in 52 overweight postmenopausal women. Fasching et al. [31] found no effect of exchanging $200 \mathrm{~g}$ of carbohydrates with $90 \mathrm{~g}$ of PUFA, MUFA, or saturated fat for one week in a randomised crossover study in eight men with insulin sensitivity, assessed with a euglycemic hyperinsulinemic clamp. Borkmann et al. [32] found no effect of substituting saturated fat for carbohydrates on insulin sensitivity in eight non-diabetic subjects, despite large changes in LDL and TG (the latter down 33\%.) The KANWU study [33] showed that a high MUFA diet for three months reduced insulin resistance, compared with a high saturated fat diet in 162 healthy subjects, but carbohydrate levels were not examined. Fish oil had no effect and the effect of MUFA was lost when fat intake was $>37 \%$ of energy. In a very small study in patients with fatty liver disease, a high MUFA Mediterranean diet improved insulin sensitivity, compared with a high carbohydrate diet $(p=0.03)$ accompanied by a reduction in liver fat [34]

A contrary result was found in the Lipgene study [35] where 472 volunteers with metabolic syndrome were randomised to one diet for 12 weeks: High MUFA or high saturated fat diets or high carbohydrate diets with and without fish oil (1.2 g/day). In the highest HOMA-IR tertile, MUFA and n3 fats lowered insulin significantly, compared with saturated fat. In the lowest HOMA-IR tertile, insulin and glucose rose with all diets, but it rose less with MUFA and N3 fats compared with saturated fat. There is regression to the mean in both these tertiles and there is no statistical contrast between the effect of diets in the different tertiles, so we don't actually know if there is a tertile/diet interaction. Triglycerides fell with N3 fats in tertiles 1 and 2, but surprisingly, not in the highest tertile with the highest TG level. Replacing carbohydrates with MUFA or saturated fat had no effect on TG in any tertile, which is contrary to the much bigger meta-analysis of Mensink et al. (3) and there is no good explanation other than strong time-related changes.

In another report from the same study, in 337 volunteers [36], the prevalence of metabolic syndrome (NECP-III) fell by $20.5 \%$ after the n-3 diet (blood pressure and TG fell), compared with the high saturated fat diet (10.6\%), high MUFA diet (12\%) diet, and high carbohydrate diet $(10.4 \%)$ $(p<0.028)$.

\section{Conclusions}

Most meta-analyses show that replacement of carbohydrates with fat lowers fasting TG and glucose and blood pressure, and increases HDL cholesterol with some differences, depending on whether the population has type 2 diabetes or not. There are some large intervention and cohort studies that show the opposite results, but these are in the minority. PUFA is probably superior to MUFA, while fish oil is superior to both.

Conflicts of Interest: The author declares no conflict of interest.

\section{References}

1. Reaven, G.M. Banting lecture 1988. Role of insulin resistance in human disease. Diabetes 1988, 37, $1595-1607$. [CrossRef] [PubMed] 
2. Kassi, E.; Pervanidou, P.; Kaltsas, G.; Chrousos, G. Metabolic syndrome: Definitions and controversies. BMC Med. 2011, 9, 48. [CrossRef] [PubMed]

3. Mensink, R.P.; Zock, P.L.; Kester, A.D.; Katan, M.B. Effects of dietary fatty acids and carbohydrates on the ratio of serum total to HDL cholesterol and on serum lipids and apolipoproteins: A meta-analysis of 60 controlled trials. Am. J. Clin. Nutr. 2003, 77, 1146-1155. [CrossRef] [PubMed]

4. Vitali, C.; Khetarpal, S.A.; Rader, D.J. Cholesterol Metabolism and the Risk of CHD: New Insights from Human Genetics. Curr. Cardiol. Rep. 2017, 19, 132. [CrossRef] [PubMed]

5. Ference, B.A.; Kastelein, J.J.P.; Ray, K.K.; Ginsberg, H.N.; Chapman, M.J.; Packard, C.J.; Laufs, U.; Oliver-Williams, C.; Wood, A.M.; Butterworth, A.S.; et al. Association of Triglyceride-Lowering LPL Variants and LDL-C-Lowering LDLR Variants with Risk of Coronary Heart Disease. JAMA 2019, 321, 364-373. [CrossRef] [PubMed]

6. Miller, M.; Sorkin, J.D.; Mastella, L.; Sutherland, A.; Rhyne, J.; Donnelly, P.; Simpson, K.; Goldberg, A.P. Poly is more effective than monounsaturated fat for dietary management in the metabolic syndrome: The muffin study. J. Clin. Lipidol. 2016, 10, 996-1003. [CrossRef] [PubMed]

7. Chen, G.C.; Szeto, I.M.; Chen, L.H.; Han, S.F.; Li, Y.J.; van Hekezen, R.; Qin, L.Q. Dairy products consumption and metabolic syndrome in adults: Systematic review and meta-analysis of observational studies. Sci. Rep. 2015, 5, 14606. [CrossRef]

8. Coulston, A.M.; Hollenbeck, C.B.; Reaven, G.M.; Swislocki, A.L.M. Persistence of Hypertriglyceridemic Effect of Low-Fat High-Carbohydrate Diets in NIDDM Patients. Diabetes Care 1989, 12, 94-101. [CrossRef]

9. Hollenbeck, C.B.; Coulston, A.M. Effects of dietary carbohydrate and fat intake on glucose and lipoprotein metabolism in individuals with diabetes mellitus. Diabetes Care 1991, 14, 774-785. [CrossRef]

10. Riccardi, G.; Rivellese, A.A.; Mokdad, A.H.; Ford, E.S.; Bowman, B.A.; Nelson, D.E.; Engelgau, M.M.; Vinicor, F.; Marks, J.S. Effects of Dietary Fiber and Carbohydrate on Glucose and Lipoprotein Metabolism in Diabetic Patients. Diabetes Care 1991, 14, 1115-1125. [CrossRef]

11. Te Morenga, L.A.; Howatson, A.J.; Jones, R.M.; Mann, J. Dietary sugars and cardiometabolic risk: Systematic review and meta-analyses of randomized controlled trials of the effects on blood pressure and lipids. Am. J. Clin. Nutr. 2014, 100, 65-79. [CrossRef] [PubMed]

12. Gibson, S.; Gunn, P.; Wittekind, A.; Cottrell, R. The Effects of Sucrose on Metabolic Health: A Systematic Review of Human Intervention Studies in Healthy Adults. Crit. Rev. Food Sci. Nutr. 2013, 53, 591-614. [CrossRef] [PubMed]

13. Howard, B.V.; Abbott, W.G.; A Swinburn, B. Evaluation of Metabolic Effects of Substitution of Complex Carbohydrates for Saturated Fat in Individuals with Obesity and NIDDM. Diabetes Care 1991, 14, 786-795. [CrossRef] [PubMed]

14. Vitale, M.; Masulli, M.; Rivellese, A.A.; Babini, A.C.; Boemi, M.; Bonora, E.; Buzzetti, R.; Ciano, O.; Cignarelli, M.; Cigolini, M.; et al. Influence of dietary fat and carbohydrates proportions on plasma lipids, glucose control and low-grade inflammation in patients with type 2 diabetes-The TOSCA.IT Study. Eur. J. Nutr. 2016, 55, 1645-1651. [CrossRef] [PubMed]

15. Vitale, M.; Masulli, M.; Calabrese, I.; Rivellese, A.A.; Bonora, E.; Signorini, S.; Perriello, G.; Squatrito, S.; Buzzetti, R.; Sartore, G.; et al. Impact of a Mediterranean Dietary Pattern and Its Components on Cardiovascular Risk Factors, Glucose Control, and Body Weight in People with Type 2 Diabetes: A Real-Life Study. Nutrients 2018, 10, 1067. [CrossRef]

16. Qian, F.; Korat, A.A.; Malik, V.; Hu, F.B. Metabolic Effects of Monounsaturated Fatty Acid-Enriched Diets Compared with Carbohydrate or Polyunsaturated Fatty Acid-Enriched Diets in Patients with Type 2 Diabetes: A Systematic Review and Meta-analysis of Randomized Controlled Trials. Diabetes Care 2016, 39, 1448-1457. [CrossRef]

17. Chen, J.P.; Chen, G.C.; Wang, X.P.; Qin, L.; Bai, Y. Dietary Fiber and Metabolic Syndrome: A Meta-Analysis and Review of Related Mechanisms. Nutrients 2017, 10, 24. [CrossRef]

18. Lu, M.; Wan, Y.; Yang, B.; Huggins, C.E.; Li, D. Effects of low-fat compared with high-fat diet on cardiometabolic indicators in people with overweight and obesity without overt metabolic disturbance: A systematic review and meta-analysis of randomised controlled trials. Br. J. Nutr. 2018, 119, 96-108. [CrossRef] 
19. Guo, X.F.; Li, X.; Shi, M.; Li, D. n-3 Polyunsaturated Fatty Acids and Metabolic Syndrome Risk: A Meta-Analysis. Nutrients 2017, 9, 703. [CrossRef]

20. Eslick, G.D.; Howe, P.R.; Smith, C.; Priest, R.; Bensoussan, A. Benefits of fish oil supplementation in hyperlipidemia: A systematic review and meta-analysis. Int. J. Cardiol. 2009, 136, 4-16. [CrossRef]

21. Wanders, A.J.; Blom, W.A.M.; Zock, P.L.; Geleijnse, J.M.; A Brouwer, I.; Alssema, M. Plant-derived polyunsaturated fatty acids and markers of glucose metabolism and insulin resistance: A meta-analysis of randomized controlled feeding trials. BMJ Open Diabetes Res. Care 2019, 7, e000585. [CrossRef] [PubMed]

22. Imamura, F.; Micha, R.; Wu, J.H.; de Oliveira Otto, M.C.; Otite, F.O.; Abioye, A.I.; Mozaffarian, D. Effects of Saturated Fat, Polyunsaturated Fat, Monounsaturated Fat, and Carbohydrate on Glucose-Insulin Homeostasis: A Systematic Review and Meta-analysis of Randomised Controlled Feeding Trials. PLoS Med. 2016, 13, e1002087. [CrossRef] [PubMed]

23. Shah, M.; Adams-Huet, B.; Garg, A. Effect of high-carbohydrate or high-cis-monounsaturated fat diets on blood pressure: A meta-analysis of intervention trials. Am. J. Clin. Nutr. 2007, 85, 1251-1256. [CrossRef] [PubMed]

24. Huntriss, R.; Campbell, M.; Bedwell, C. The interpretation and effect of a low-carbohydrate diet in the management of type 2 diabetes: A systematic review and meta-analysis of randomised controlled trials. Eur. J. Clin. Nutr. 2018, 72, 311-325. [CrossRef] [PubMed]

25. Mansoor, N.; Vinknes, K.J.; Veierød, M.B.; Retterstøl, K. Effects of low-carbohydrate diets v. low-fat diets on body weight and cardiovascular risk factors: A meta-analysis of randomised controlled trials. Br. J. Nutr. 2016, 115, 466-479. [CrossRef]

26. Luscombe-Marsh, N.D.; Noakes, M.; Buckley, J.; Wittert, G.A.; Yancy, W.S.; Brinkworth, G.D.; Tay, J.; Thompson, C.H. A Very Low-Carbohydrate, Low-Saturated Fat Diet for Type 2 Diabetes Management: A Randomized Trial. Diabetes Care 2014, 37, 2909-2918. [CrossRef]

27. Tay, J.; Luscombe-Marsh, N.D.; Thompson, C.H.; Noakes, M.; Buckley, J.; Wittert, G.A.; Yancy, W.S., Jr.; Brinkworth, G.D. Comparison of low- and high-carbohydrate diets for type 2 diabetes management: A randomized trial. Am. J. Clin. Nutr. 2015, 102, 780-790. [CrossRef]

28. Tay, J.; Thompson, C.H.; Luscombe-Marsh, N.D.; Wycherley, T.P.; Noakes, M.; Buckley, J.D.; Wittert, G.A.; Yancy, W.S., Jr.; Brinkworth, G.D. Effects of an energy-restricted low-carbohydrate, high unsaturated fat/low saturated fat diet versus a high-carbohydrate, low-fat diet in type 2 diabetes: A 2-year randomized clinical trial. Diabetes Obes. Metab. 2018, 20,858-871. [CrossRef]

29. Tardy, A.L.; Lambert-Porcheron, S.; Malpuech-Brugère, C.; Giraudet, C.; Rigaudière, J.P.; Laillet, B.; Leruyet, P.; Peyraud, J.L.; Boirie, Y.; Laville, M.; et al. Dairy and industrial sources of trans fat do not impair peripheral insulin sensitivity in overweight women. Am. J. Clin. Nutr. 2009, 90, 88-94. [CrossRef]

30. Bendsen, N.T.; Haugaard, S.B.; Larsen, T.M.; Chabanova, E.; Stender, S.; Astrup, A. Effect of trans-fatty acid intake on insulin sensitivity and intramuscular lipids-a randomized trial in overweight postmenopausal women. Metabolism 2011, 60, 906-913. [CrossRef]

31. Fasching, P.; Ratheiser, K.; Schneeweiss, B.; Rohac, M.; Nowotny, P.; Waldhäusl, W. No effect of short-term dietary supplementation of saturated and poly-and monounsaturated fatty acids on insulin secretion and sensitivity in healthy men. Ann. Nutr. Metab. 1996, 40, 116-122. [CrossRef] [PubMed]

32. Borkman, M.; Campbell, L.V.; Chisholm, D.J.; Storlien, L.H. Comparison of the effects on insulin sensitivity of high carbohydrate and high fat diets in normal subjects. J. Clin. Endocrinol. Metab. 1991, 72, $432-437$. [CrossRef] [PubMed]

33. Vessby, B.; Uusitupa, M.; Hermansen, K.; Riccardi, G.; Rivellese, A.A.; Tapsell, L.C.; Nälsén, C.; Berglund, L.; Louheranta, A.; Rasmussen, B.M.; et al. Substituting dietary saturated for monounsaturated fat impairs insulin sensitivity in healthy men and women: The KANWU Study. Diabetologia 2001, 44, 312-319. [CrossRef] [PubMed]

34. Ryan, M.C.; Itsiopoulos, C.; Thodis, T.; Ward, G.; Trost, N.; Hofferberth, S.; O'Dea, K.; Desmond, P.V.; Johnson, N.A.; Wilson, A.M. The Mediterranean diet improves hepatic steatosis and insulin sensitivity in individuals with non-alcoholic fatty liver disease. J. Hepatol. 2013, 59, 138-143. [CrossRef] [PubMed] 
35. Yubero-Serrano, E.M.; Delgado-Lista, J.; Tierney, A.C.; Perez-Martinez, P.; Garcia-Rios, A.; Alcala-Diaz, J.F.; Castaño, J.P.; Tinahones, F.J.; A Drevon, C.; Defoort, C.; et al. Insulin resistance determines a differential response to changes in dietary fat modification on metabolic syndrome risk factors: The LIPGENE study. Am. J. Clin. Nutr. 2015, 102, 1509-1517. [CrossRef] [PubMed]

36. Paniagua, J.A.; Pérez-Martinez, P.; Gjelstad, I.M.; Tierney, A.C.; Delgado-Lista, J.; Defoort, C.; Blaak, E.E.; Risérus, U.; Drevon, C.A.; Kiec-Wilk, B.; et al. A low-fat high-carbohydrate diet supplemented with long-chain $\mathrm{n}-3$ PUFA reduces the risk of the metabolic syndrome. Atherosclerosis 2011, 218, 443-450. [CrossRef] [PubMed]

(C) 2019 by the author. Licensee MDPI, Basel, Switzerland. This article is an open access article distributed under the terms and conditions of the Creative Commons Attribution (CC BY) license (http://creativecommons.org/licenses/by/4.0/). 